\title{
ЭФФЕКТИВНОСТЬ СРЕДНЕСРОЧНОГО ПЛАНИРОВАНИЯ ФЕДЕРАЛЬНЫХ РАСХОДОВ В ГЕРМАНИИ: ГЛАВНЫЕ СТРУКТУРНЫЕ СДВИГИ
}

\begin{abstract}
Аннотация. В статье изучается эффективность среднесрочного финансового планирования в Германии на основе анализа структурных сдвигов в расходной части федерального бюджета. Используются данные об исполнении трёх 5-летних планов (на 2002-2006 г2., 2007-2011 г2., 2012-2016 г2.) и о 5-летнем плане на 2017-2021 г2. Автор проанализировал динамику и структуру федеральных расходов по перекрёстной классификации (одновре́менно по функииональной и экономической классификациям), выделив промежуточные и итоговые структурные сдвиги. Результаты расчётов позволили сделать выводы о чёткой последовательности осуществления структурных сдвигов в расходной части федерального бюджета Германии. Основное содержание этих сдвигов заключается в акиентировании федеральных расходов на здравоохранении и образовании/науке за счёт сокращения процентных выплат по госдолгу.
\end{abstract}

Ключевые слова: пятилетнее финансовое планирование в Германии, расходы федерального бюджета, перекрестная классификачия, динамика расходов, структура расходов.

Германия имеет более чем 50-летний опыт среднесрочного (5-летнего) планирования федерального бюджета. Анализ его эффективности с точки зрения точности реализации бюджетных проектировок по федеральным расходам в рамках трёх 5-летних финансовых планов в 2002-2016 гг. свидетельствует: качество планирования оценивается по международной методологии как наивысшее. В указанный период отклонения фактических расходов от запланированных последовательно уменьшались (и в целом, и по функциональной/экономической классификации, и в абсолютном/относительном измерении) ${ }^{1}$.

Для всесторонней оценки эффективности среднесрочного планирования федеральных расходов необходимо определить не только точность финансовых планов, но и сущность осуществлённых/намечаемых структурных сдвигов в расходной части федерального бюджета Германии. В предлагаемой статье выявляется степень последовательности реализуемых изменений и рассматривается основное содержание указанных сдвигов в течение трёх исполненных 5-леток (2002-2016 гг.) и5-летки на 2017-2021 гг.

\section{Динамика расходов по перекрестной классификации в 2002-2021 гг.}

Данные о динамике федеральных расходов по перекрёстной (одновре́менно по функциональной/экономической) классификации в течение трёх исполненных 5-леток (2002-2016 гг.) и 5-летки на 2017-2021 гг. представлены в таблице 1.

\footnotetext{
(C) Грачёва Мария Владимировна - кандидат экономических наук, ведущий научный сотрудник, Национальный исследовательский институт мировой экономики и международных отношений имени Е.M. Примакова РАН. Aдpec: 117997, Россия, Москва, ул. Профсоюзная, д. 23. E-mail: mgracheva@mail.ru.
}

DOI: http://dx.doi.org/10.15211/vestnikieran12019114119

${ }^{1}$ Ссылка на статью «Эффективность среднесрочного планирования федеральных расходов в Германии: точность бюджетных проектировок». 
Таблица 1

Расходы федерального бюджета (ФБ) Германии по перекрестной классификации (ФК/ЭК)

\begin{tabular}{|c|c|c|c|c|c|c|c|c|c|c|}
\hline \multirow{4}{*}{$\Phi К$} & \multicolumn{8}{|c|}{ ЭК } & \multirow{2}{*}{\multicolumn{2}{|c|}{$\begin{array}{c}\text { Прирост расходов, } \\
2017-2021 \text { (план)/ } \\
2002-2006 \text { (факт) }\end{array}$}} \\
\hline & \multicolumn{2}{|c|}{$\begin{array}{l}2002-2006 \\
(\text { факт) }\end{array}$} & \multicolumn{2}{|c|}{$\begin{array}{l}2007-2011 \\
\text { (факт) }\end{array}$} & \multicolumn{2}{|c|}{$\begin{array}{l}2012-2016 \\
\text { (факт) }\end{array}$} & \multicolumn{2}{|c|}{$\begin{array}{l}2017-2021 \\
\text { (план) }\end{array}$} & & \\
\hline & $\begin{array}{l}\text { Теку- } \\
\text { щие }\end{array}$ & $\begin{array}{c}\text { Капи- } \\
\text { тальные }\end{array}$ & $\begin{array}{c}\text { Теку- } \\
\text { щие }\end{array}$ & $\begin{array}{c}\text { Капи- } \\
\text { тальные }\end{array}$ & $\begin{array}{c}\text { Теку- } \\
\text { щие }\end{array}$ & $\begin{array}{c}\text { Капи- } \\
\text { тальные }\end{array}$ & $\begin{array}{l}\text { Теку- } \\
\text { щие }\end{array}$ & $\begin{array}{c}\text { Капи- } \\
\text { тальные }\end{array}$ & $\begin{array}{l}\text { Теку- } \\
\text { щие }\end{array}$ & Капитальные \\
\hline & \multicolumn{8}{|c|}{ млрд евро } & \multicolumn{2}{|r|}{$\%$} \\
\hline $\begin{array}{l}\text { 701. Государственные службы общего } \\
\text { назначения }\end{array}$ & 198,6 & 14,5 & 190,5 & 21,5 & 157,3 & 43,9 & 129,3 & 30,8 & $-34,9$ & $+112,4$ \\
\hline 702. Оборона & 119,5 & 1,8 & 135,4 & 1,3 & 140,9 & 1,5 & 169,2 & 1,4 & $+41,6$ & $-22,2$ \\
\hline $\begin{array}{l}\text { 703. Общественный порядок и безопас- } \\
\text { ность }\end{array}$ & 15,2 & 1,3 & 18,4 & 1,6 & 22,8 & 1,5 & 29,7 & 2,5 & $+95,4$ & $+92,3$ \\
\hline 704. Экономические вопросы & 73,4 & 68,4 & 68,8 & 69,0 & 70,5 & 70,1 & 77,3 & 89,9 & $+5,3$ & $+31,4$ \\
\hline 705. Охрана окружающей среды & 1,3 & 1,0 & 1,5 & 2,0 & 1,7 & 3,7 & 2,0 & 6,4 & $+53,8$ & $+540,0$ \\
\hline $\begin{array}{l}\text { 706. Жилищная и коммунальная инфра- } \\
\text { структура }\end{array}$ & 2,9 & 7,5 & 1,2 & 8,1 & 2,0 & 7,5 & 0,4 & 11,0 & $-86,2$ & $+46,7$ \\
\hline 707. Здравоохранение & 13,5 & & 48,4 & & 68,3 & & 80,2 & & $+494,1$ & \\
\hline 708. Отдых, культура, религия & 7,0 & 1,0 & 7,5 & 1,4 & 9,5 & 1,1 & 12,0 & 1,7 & $+71,4$ & $+70,0$ \\
\hline 709. Образование и наука & 36,4 & 13,2 & 49,2 & 14,7 & 71,5 & 14,7 & 90,0 & 16,4 & $+147,3$ & $+24,2$ \\
\hline 710. Социальная защита & 673,4 & 0,9 & 782,2 & & 794,9 & 0,2 & 916,3 & 1,4 & $+36,1$ & $+55,6$ \\
\hline $\begin{array}{l}\text { Pacходы, распределенные по ФК/ЭК } \\
\left(\sum \text { расходов по ФК/ЭК) }\right.\end{array}$ & 1141,0 & 109,6 & 1303,0 & 119,6 & 1339,5 & 144,2 & 1506,4 & 161,5 & $+32,0$ & $+47,4$ \\
\hline $\begin{array}{l}\text { Совокупные расходы ФБ, распределенны } \\
\text { по ФК/ЭК }\end{array}$ & \multicolumn{2}{|c|}{1250,6} & \multicolumn{2}{|c|}{1422,6} & \multicolumn{2}{|c|}{1483,7} & \multicolumn{2}{|c|}{1667,9} & \multicolumn{2}{|r|}{$+33,4$} \\
\hline
\end{tabular}

\begin{tabular}{|l|c|c|c|c|}
\hline \multicolumn{1}{|c|}{ Показатель } & $\begin{array}{c}2002-2006 \\
\text { (факт) }\end{array}$ & $\begin{array}{c}2007-2011 \\
\text { (факт) }\end{array}$ & $\begin{array}{c}2012-2016 \\
\text { (факт) }\end{array}$ & $\begin{array}{c}2017-2021 \\
\text { (план) }\end{array}$ \\
\cline { 2 - 6 } & \multicolumn{4}{|c|}{ млрд евро } \\
\hline Нераспределенные расходы/ корректировки - всего, в т.ч. & $+27,9$ & $+22,3$ & $+55,0$ & $+53,1$ \\
\hline $\begin{array}{l}\text { нераспределенные по ФК } \\
\text { нераспределенные по ЭК }\end{array}$ & $+27,9$ & $+22,3$ & $+36,4$ & $+60,4$ \\
\hline Совокупные расходы ФБ & 1278,5 & 1444,9 & 1538,6 & 1721,0 \\
\hline
\end{tabular}

Доля нераспределенных расходов/ корректировок в совокупных расходах ФБ, \%

2,2

1,5

3,6

3,1

Не все совокупные расходы федерального бюджета поддаются распределению в двух разрезах (ФК и ЭК) одновре́менно, но доля нераспределённых по ФК или ЭК расходов/корректировок в совокупных расходах является невысокой, составляя в среднем 2,6\%.

На фоне средних темпов прироста распределённых совокупных расходов $(+32,4 \%$ по текущим и $+47,4 \%$ по капитальным расходам) выделяются: с одной стороны, четыре направления-лидера роста; с другой стороны, четыре направления, показавшие сокращение или крайне низкий рост. К самым быстрорастущим относятся: капитальные расходы на охрану окружающей среды (рост более чем в 6 раз), текущие расходы на здравоохранение (рост почти в 6 ра3), текущие расходы на образование/науку (рост в 2,5 раза) и капитальные расходы на госслужбы общего назначения (рост вдвое). К падающим/стагнирующим направлениям относятся: текущие расходы на жилищную и коммунальную инфраструктуру $(-86,2 \%)$, текущие расходы на госслужбы общего назначения $(-34,9 \%)$, капитальные расходы на оборону $(-22,2 \%)$ и текущие расходы на экономику $(+5,4 \%)$.

При переходе от первой ко второй и третьей исполненным 5-леткам и далее к четвёртой 5-летке 2017-2021 гг. произошло 57 изменений текущих и капитальных расходов. При этом лишь в восьми случаях отмечались разнонаправленные колебания, тогда как 49 изменений оказались строго однонаправленными. 


\section{Структура расходов по перекрёстной классификации в 2002-2021 гг.}

Данные об изменении объёмов среднегодовых федеральных расходов в 2017-2021 гг. относительно первой из анализируемых 5-леток (2002-2006 гг.), а также о структуре этих изменений по перекрёстной (функциональной/экономической) классификации (промежуточные структурные сдвиги) представлены в таблице 2. За 16 лет совокупные среднегодовые расходы, распределённые по ФК/ЭК, увеличились на 83,5 млрд евро, в т.ч. текущие расходы на 73,1 млрд евро (88\% итогового прироста), капитальные расходы - на 10,4 млрд евро (12\% итогового прироста).

Таблица 2

Структура изменения расходов федерального бюджета (ФБ) Германии по перекрестной классификации (ФК/ЭК) в 2017-2021 гг. по сравнению с 2002-2006 гг.

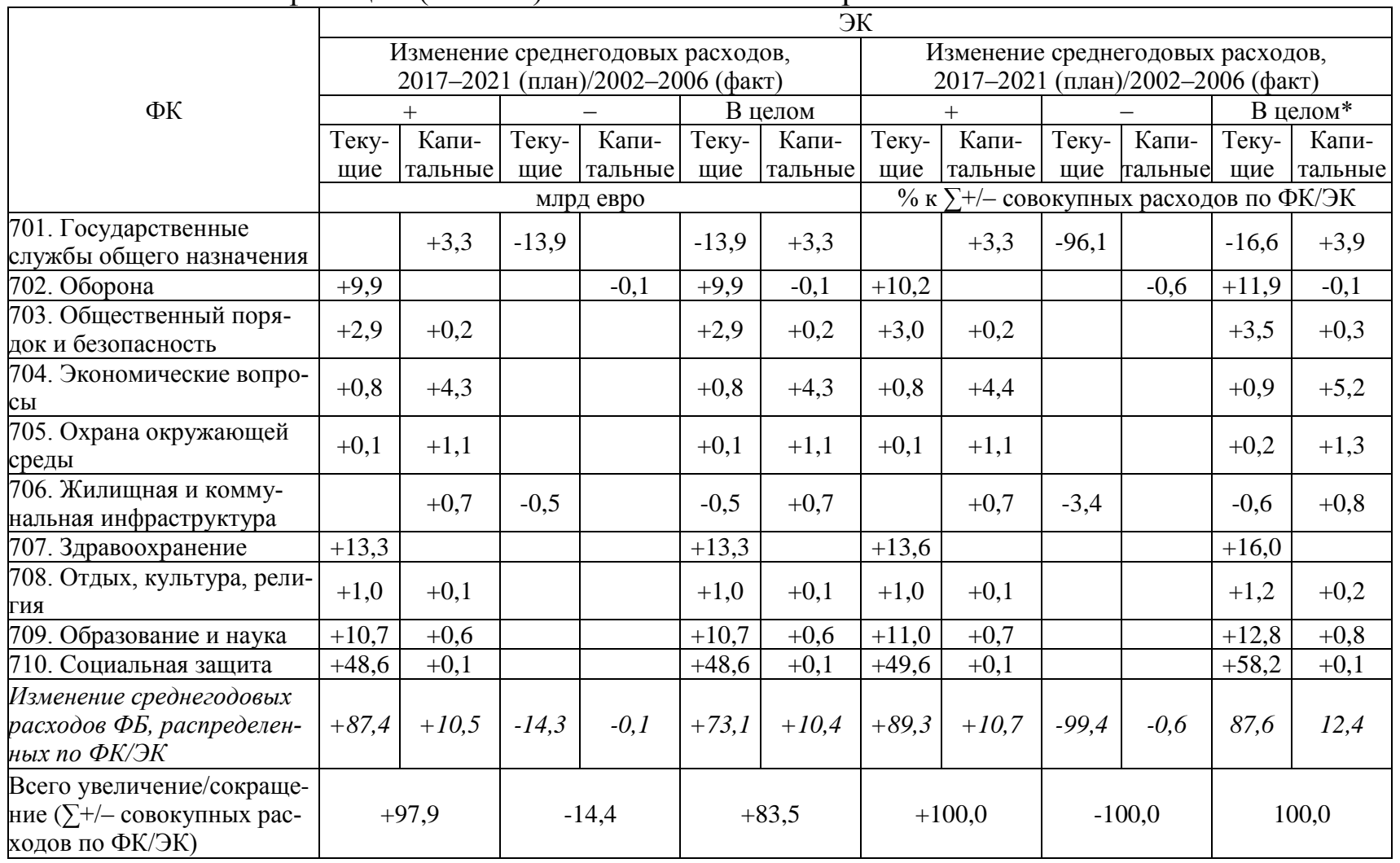

* промежуточные структурные сдвиги.

Среди 19 направлений расходов (текущих/капитальных по десяти разделам ФК; капитальные расходы на здравоохранение в федеральном бюджете отсутствовали) сокращение объёмов произошло лишь на трёх направлениях. Общая сумма сокращений составила 14,4 млрд евро, главным фактором падения стали текущие расходы на госслужбы общего назначения (-13,9 млрд евро, или 96,1\%). На остальных направлениях объёмы увеличились (на общую сумму 97,9 млрд евро), главными факторами роста стали текущие расходы на соцзащиту (+48,6 млрд евро, или 49,6\%) и на здравоохранение (+13,3 млрд евро, или 13,6\%). Заметно возросли также текущие расходы на образование/науку $(+10,7$ млрд евро, или 11,0\%) и на оборону (+9,9 млрд евро, или 10,2\%). Все прочие показатели прироста не превысили 5 млрд евро (5\% общей суммы увеличения), самыми крупными среди них стали капитальные расходы на экономику $(+4,3$ млрд евро, или 4,4\%) и на госслужбы общего назначения (+3,3 млрд евро, или $3,3 \%)$. 
Данные о структуре федеральных расходов по перекрестной (функциональной/экономической) классификации в течение трёх исполненных 5-леток (2002-2016 гг.) и 5-летки на 2017-2021 гг., а также изменения долей расходов в 5-летке 2017-2021 гг. по сравнению с 5леткой 2002-2006 гг. (итоговые структурные сдвиги) представлены в таблице 3. Соотношение между текущими и капитальными расходами изменилось, но не слишком сильно: доля первых понизилась, а доля вторых повысилась менее чем на 1 п.п. Это произошло потому, что важнейший раздел капитальных расходов по ФК - экономические вопросы - показал рост на среднем уровне. Два других раздела с весьма крупными капитальными расходами (образование/наука и жилищная/коммунальная инфраструктура) выросли на уровнях немного выше/ ниже среднего. А два указанных выше раздела с экстремально высоким ростом (охрана окружающей среды) и с падением (оборона) не могли оказать серьёзного влияния на долю капитальных расходов вследствие незначительности своих объёмов.

Таблица 3

Структура расходов федерального бюджета (ФБ) Германии по перекрестной классификации (ФК/ЭК)

\begin{tabular}{|c|c|c|c|c|c|c|c|c|c|c|}
\hline \multirow{4}{*}{$\Phi К$} & \multicolumn{8}{|c|}{ ЭК } & \multirow{2}{*}{\multicolumn{2}{|c|}{$\begin{array}{l}\text { Изменение доли, } \\
\text { 2017-2021 (план)/ } \\
\text { 2002-2006 (факт)* }\end{array}$}} \\
\hline & \multicolumn{2}{|c|}{ 2002-2006 (факт) } & \multicolumn{2}{|c|}{ 2007-2011 (факт) } & \multicolumn{2}{|c|}{ 2012-2016 (факт) } & \multicolumn{2}{|c|}{ 2017-2021 (план) } & & \\
\hline & $\begin{array}{l}\text { Теку- } \\
\text { щие }\end{array}$ & $\begin{array}{c}\text { Капи- } \\
\text { тальные }\end{array}$ & $\begin{array}{l}\text { Теку- } \\
\text { щие }\end{array}$ & $\begin{array}{c}\text { Капи- } \\
\text { тальные }\end{array}$ & $\begin{array}{l}\text { Теку- } \\
\text { щие }\end{array}$ & $\begin{array}{c}\text { Капи- } \\
\text { тальные }\end{array}$ & $\begin{array}{l}\text { Теку- } \\
\text { щие }\end{array}$ & $\begin{array}{c}\text { Капи- } \\
\text { тальные }\end{array}$ & Текущие & $\begin{array}{c}\text { Капи- } \\
\text { тальные }\end{array}$ \\
\hline & \multicolumn{2}{|c|}{$\begin{array}{l}\% \text { к } \sum \text { сов по ФК } \\
/ \text { ЭК в 2002-2006 } \\
\end{array}$} & \multicolumn{2}{|c|}{\begin{tabular}{|c|}
$\%$ к $\sum$ сов по $Ф К /$ \\
ЭК в 2007-2011 \\
\end{tabular}} & \multicolumn{2}{|c|}{ 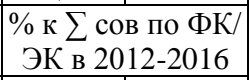 } & \multicolumn{2}{|c|}{ 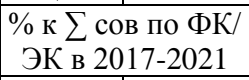 } & \multicolumn{2}{|c|}{ п.п. } \\
\hline $\begin{array}{l}701 . \text { Государственные служ- } \\
\text { бы общего назначения }\end{array}$ & 15,9 & 1,2 & 13,4 & 1,5 & 10,6 & 3,0 & 7,8 & 1,8 & $-8,1$ & $+0,7$ \\
\hline 702. Оборона & 9,6 & 0,1 & 9,5 & 0,1 & 9,5 & 0,1 & 10,1 & 0,1 & $+0,6$ & $-0,1$ \\
\hline $\begin{array}{l}\text { 703. Общественный порядок } \\
\text { и безопасность }\end{array}$ & 1,2 & 0,1 & 1,3 & 0,1 & 1,5 & 0,1 & 1,8 & 0,1 & $+0,6$ & \\
\hline 704. Экономические вопросы & 5,9 & 5,5 & 4,8 & 4,9 & 4,8 & 4,7 & 4,6 & 5,4 & $-1,2$ & $-0,1$ \\
\hline $\begin{array}{l}\text { 705. Охрана окружающей } \\
\text { среды }\end{array}$ & 0,1 & 0,1 & 0,1 & 0,1 & 0,1 & 0,2 & 0,1 & 0,4 & & $+0,3$ \\
\hline $\begin{array}{l}\text { 706. Жилищная и комму- } \\
\text { нальная инфраструктура }\end{array}$ & 0,2 & 0,6 & 0,1 & 0,6 & 0,1 & 0,5 & & 0,7 & $-0,2$ & $+0,1$ \\
\hline 707. Здравоохранение & 1,1 & & 3,4 & & 4,6 & & 4,8 & & $+3,7$ & \\
\hline $\begin{array}{l}\text { 708. Отдых, культура, рели- } \\
\text { гия }\end{array}$ & 0,6 & 0,1 & 0,5 & 0,1 & 0,6 & 0,1 & 0,7 & 0,1 & $+0,2$ & \\
\hline 709. Образование и наука & 2,9 & 1,1 & 3,5 & 1,0 & 4,8 & 1,0 & 5,4 & 1,0 & $+2,5$ & $-0,1$ \\
\hline 710. Социальная защита & 53,8 & 0,1 & 55,0 & & 53,6 & & 54,9 & 0,1 & $+1,1$ & \\
\hline $\begin{array}{l}\text { Pасходы ФБ, распределенные } \\
\text { по ФК/ЭК }\end{array}$ & 91,2 & 8,8 & 91,6 & 8,4 & 90,3 & 9,7 & 90,3 & 9,7 & $-0,9$ & $+0,9$ \\
\hline $\begin{array}{l}\text { Совокупные расходы ФБ, } \\
\text { распределенные по ФК/ЭК } \\
\left(\sum \text { сов по ФК/ЭК) }\right.\end{array}$ & \multicolumn{2}{|c|}{100,0} & \multicolumn{2}{|c|}{100,0} & \multicolumn{2}{|c|}{100,0} & \multicolumn{2}{|c|}{100,0} & & \\
\hline
\end{tabular}

* итоговые структурные сдвиги.

Единственным заметным как по темпу роста, так и по объёму направлением оказались капитальные расходы на госслужбы общего назначения, а именно на экономическую помощь развивающимся странам. Именно эти затраты и стали ключевым фактором небольшого увеличения удельного веса капитальных расходов в совокупных расходах (на 0,9 п.п.).

Главные же структурные сдвиги произошли в рамках текущих расходов (указаны изменения, на которые пришлось более половины итоговых отрицательных/положительных приростов долей текущих расходов в п.П.; указанные итоговые приросты составили $-9,5$ п.П. и $+8,6$ п.П. соответственно):

•с одной стороны, сократилась доля госслужб общего назначения (на 8,1 п.п.), в основном за счёт процентных выплат по госдолгу; 
- с другой стороны, выросли доли: а) здравоохранения (+3,7 п.п.), из-за расходов на обязательное медицинское страхование; б) образования/науки (+2,5 п.п.), в основном благодаря финансированию науки и стипендий/поддержки молодых учёных.

Сравнение данных табл. 2 и 3 (промежуточных и итоговых структурных сдвигов) показывает, что в части падения расходов основным фактором с обеих точек зрения стали текущие расходы на госслужбы общего назначения.

В части же наращивания расходов выявилось расхождение: с точки зрения промежуточных структурных сдвигов основными факторами явились текущие расходы на соцзащиту и на здравоохранение, а с точки зрения итоговых структурных сдвигов - текущие расходы на здравоохранение и на образование/науку.

Указанная разница объясняется тем, что наибольшие итоговые структурные сдвиги произошли у тех разделов ФК, которые продемонстрировали наибольшее превышение промежуточных структурных сдвигов над начальными структурными показателями (долями разделов в 2002-2006 гг.). Так, у текущих расходов на соцзащиту начальный структурный показатель (их доля в совокупных расходах в 2002-2006 гг.) составил 53,8\% (см. табл. 3), а показатель промежуточных структурных сдвигов (доля в изменении в 2017-2021 гг. относительно 20022006 гг. в целом) составил 58,2\% (см. табл. 2). Разрыв между промежуточным и начальным уровнями составил 4,4 п.п. Соответствующий разрыв у текущих расходов на здравоохранение достиг 14,9 п.П., у текущих расходов на образование/науку - 9,9 п.п., поэтому именно эти разделы и стали лидерами по итоговым структурным сдвигам. У всех остальных разделов указанные индикаторы оказались менее 3 п.п.

\section{Выводы}

Проведённые расчёты позволяют сделать следующие выводы. Во-первых, анализ динамики федеральных расходов в 2002-2021 гг. свидетельствует о том, что большинство (86\%) прошлых и будущих изменений являются однонаправленными, тем самым обеспечивается достаточно твёрдая последовательность в осуществлении политики финансового планирования.

Во-вторых, рассмотрение структурных сдвигов в расходной части федерального бюджета в 2002-2021 гг. позволяет выявить суть происходящих перемен, а именно проигравшие и выигравшие направления расходов. Успешное проведение политики долгового тормоза (сокращения госдолга и процентов по нему) в целях ликвидации бюджетного дефицита привело к сокращению доли текущих расходов на госслужбы общего назначения на 8,1 п.п. Главными бенефициарами стали здравоохранение и образование/наука (их совокупная доля в текущих расходах выросла на 6,2 п.п.).

Таким образом, политику 5-летнего финансового планирования в части расходов федерального бюджета Германии следует оценить как весьма эффективную: точность реализации проектировок повышается, изменения осуществляются в соответствии с чёткой и ясной логикой, выигрывают от структурных сдвигов сферы, непосредственно нацеленные на повышение качества жизни населения.

\section{References}

Finanzplan des Bundes 2002 bis 2006. Deutscher Bundestag. 2002. URL: http://dipbt.bundestag.de/dip21/btd/14/097/1409751.pdf.

Finanzplan des Bundes 2003 bis 2007. Deutscher Bundestag. 2003. URL: http://dipbt.bundestag.de/dip21/btd/15/015/1501501.pdf.

Finanzplan des Bundes 2004 bis 2008. Deutscher Bundestag. 2004. URL: 
http://dip21.bundestag.de/dip21/btd/15/036/1503661.pdf.

Finanzplan des Bundes 2005 bis 2009. Deutscher Bundestag. 2006. URL: http://dip21.bundestag.de/dip21/btd/16/007/1600751.pdf.

Finanzplan des Bundes 2006 bis 2010. Deutscher Bundestag. 2006. URL: http://dip21.bundestag.de/dip21/btd/16/023/1602301.pdf.

Finanzplan des Bundes 2007 bis 2011. Deutscher Bundestag. 2007. (URL: http://dip21.bundestag.de/dip21/btd/16/060/1606001.pdf.

Finanzplan des Bundes 2008 bis 2012. Deutscher

Bundestag. 2008. URL: http://dip21.bundestag.de/dip21/btd/16/099/1609901.pdf.

Finanzplan des Bundes 2009 bis 2013. Deutscher Bundestag. 2009. URL: http://dip21.bundestag.de/dip21/btd/16/136/1613601.pdf.

Finanzplan des Bundes 2010 bis 2014. Deutscher Bundestag. 2010. URL: http://dipbt.bundestag.de/dip21/btd/17/025/1702501.pdf.

Finanzplan des Bundes 2011 bis 2015. Deutscher http://dip21.bundestag.de/dip21/btd/17/066/1706601.pdf.

Finanzplan des Bundes 2012 bis 2016. Deutscher http://dipbt.bundestag.de/dip21/btd/17/102/1710201.pdf.

Finanzplan des Bundes 2013 bis 2017. Deutscher http://dip21.bundestag.de/dip21/btd/17/143/1714301.pdf.

Finanzplan des Bundes 2014 bis 2018. Deutscher http://dipbt.bundestag.de/dip21/btd/18/020/1802001.pdf.

Finanzplan des Bundes 2015 bis 2019. Deutscher http://dipbt.bundestag.de/dip21/btd/18/055/1805501.pdf.

Finanzplan des Bundes 2016 bis 2020. Deutscher http://dip21.bundestag.de/dip21/btd/18/092/1809201.pdf.

Finanzplan des Bundes 2017 bis 2021. Deutscher http://dip21.bundestag.de/dip21/btd/18/130/1813001.pdf.

\section{Efficiency of the medium-term planning of federal expenditures in Germany: main structural changes}

Author. Maria Gracheva, Candidate of Sciences (Economics), Leading Researcher, Primakov National Research Institute of World Economy and International Relations, Russian Academy of Sciences. Address: 23, Profsoyuznaya str., Moscow, Russia, 117997. E-mail: mgracheva@mail.ru.

Abstract. The paper examines the efficiency of medium-term financial planning in Germany from the point of view of the essence of structural changes in the expenditure part of the federal budget. The author used the data on the execution of three five-year plans (for 2002-2006, 20072011, 2012-2016) and on the five-year plan for 2017-2021. The dynamics and structure of federal expenditures by cross-classification (simultaneously by functional and economic classifications) were analyzed. At the same time, intermediate and final structural shifts were identified. The results of the calculations led to the conclusions about a clear consistency of structural changes in the expenditure part of Germany's federal budget and about the main content of these shifts, which is to increase the emphasis of federal spending on health and education/science by reducing interest payments on state debt.

Key words: five-year financial planning in Germany, federal budget's expenses, crossclassification, the dynamics of expenses, the structure of expenses.

DOI: http://dx.doi.org/10.15211/vestnikieran12019114119

Научно-аналитический вестник ИЕ РАН, 2019, №1 